ant Myrmica. In geology and geography, continued progress is reported in the study of important fossils from the coal vmeasures, in J. Phemister's gravimeter survey of the Highlands of Scotland, and W. C. Jardine's work on the relation between shore-lines and river-valley development, with particular reference to the Southern Uplands of Scotland.

\section{EUROPEAN PRODUCTIVITY AGENCY}

A RECENT issue of the Information Bulletin of the European Productivity Agency of the Organization for European Economic Co-operation describes the work of the Agency's Human Factors Division (6-7; December 1954-January 1955).

The Human Factors Division was the last of the five operational divisions of the Agency to be developed, and has not yet reached its final shape and structure. It deals with those human aspects of productivity which are the daily concern of men and women at all levels in industry.

Three sections of the Division were envisaged to cover three aspects of its work : man as an individual ; man as a member of a group or a number of groups; and, thirdly, man as a member of a trade union.

The first aspect of the work in the Division impinges on a variety of sciences and technologies, including physiology, psychology and production engineering, and covers the adaptation of machinery and physical conditions of work to the obtaining of optimum results. This field of research is better known and more highly developed in Europe than others with which the Division has to deal, and the Division therefore tends to concentrate on encouraging and supporting the work of local, national and international institutions which have already specialized in this research. Where such institutions do not exist, the Division aims at encouraging their creation.

The second section of the Division's programme deals with the sociological aspects of productivity. It is concerned not only with techniques, but also with educational processes. In sociological problems of work, Europe is, in general, behind America. In this field, the Division will have the task of encour. aging original research work and education by organizing visits to America by young men or experts from Europe who have already begun to study these subjects, and by similar visits from one European country to another. Congresses and seminars are being organized and American consultants are being appointed to disseminate in Europe the best results of American learning and practice. For example, the recognition given to the importance of the foreman and his training in technical and social skills has not been widely accepted in Europe or its consequences fully recognized. The tendency to concentrate attention on recently developed industries, particularly the manufacturing industry, has meant that the human problems of utilities and commercial firms have been overlooked. The Division is also interested in such public services as railways, and one of its projects aims at organizing a pilot analysis of human factor problems in the railways of Europe. Study will also be undertaken of office work in banks, insurance companies and commercial firms.

The third section of the work of the Human Factors Division is concerned with trade unions and trade unionism in general. What distinguishes this so-called section from the others is the method of approach. It tries to bring to the door of trade union organizations in Europe the techniques, ideas and principles which are the basis of productivity in general. If the drive for European productivity is to be effective, it must involve not only the enterprises, the managers, the head men of European industry; it must also reach the workers.

Some of the activities in this section are of a direct educational nature. Others tend to place at the disposal of trade union organizations in various countries all the information which can be found in every field, either in America or in Europe. Lecturers and American consultants who are themselves experienced trade unionists are recruited so that they may share their experiences and discuss them with their European colleagues. European consultants and lecturers, who form a panel arranged within the Division, are ready to organize courses for European trade unionists.

The work of this Division is not in any sense isolated from the work of the other divisions of the Agency. A division with which the Human Factors Division has to work in close unison is the Business Management Division. Another is the Economic Factors Division, which is concerned more specifically with economic problems. Yet another is the Agricultural Division, where human factors are just as important as they are in industry. In short, the Human Factors Division is at the service of the Agency as a whole, for the human element can never be dissociated from productivity.

\section{THE PSYCHOLOGIST AND PERSONNEL MANAGEMENT}

$\mathrm{D}$ ISCUSSING the role of the psychologist in personnel management, Dennis McMahon suggests that the psychologist is useful to the personnel manager because he is trained and experienced in tackling personnel problems in a scientific fashion. 'Scientific' has nothing to do with apparatus and relatively little to do with specialized knowledge; it has to do with approach, with method (Personnel Management, 37, No. 331; March 1955).

Sketching the way in which occupational psychology has developed in recent years, McMahon shows that in the 1920's and 1930's the topics engaging the attention of psychologists were work-study, training, selection, lighting and fatigue. Attempts were made to generalize from the results that were achieved, but these broke down; what was applicable in one industrial situation was totally inadequate in another. Human factors often arose which completely nullified the results of carefully planned scientific experiments.

Despite this, some recent researches in the field of employee relations have produced results which stand up as 'general findings' in industrial situations. These are few and fall into the category of 'blinding glimpses of the obvious'. Among them are the following:

(1) Workers who are kept informed of how they are doing, who have knowledge of results, do better than less intelligently treated workers.

(2) Success follows the supervisor: when supervisors have been moved around, production-rates tend to be moved around with them.

(3) Supervisors who are employee-centred get more out of their workers than do the autocrats, or the more technically minded supervisors. 
(4) On the whole, small working groups or teams do better than large ones.

(5) Workers who complain about the canteen and other things are usually complaining about something else but have displaced their resentment on to a handy 'whipping-boy'.

(6) Groups which set their own production targets after free discussion do better than groups which have their goals set for them-even when the setting has been done by enlightened and kindly masters.

\section{STRENGTH OF THE SHELL OF THE HEN'S EGG}

\author{
By Dr. J. BROOKS and H. P. HALE
}

Low Temperature Station for Research in Biochemistry and Biophysics, University of Cambridge, and Department of Scientific and Industrial Research

ITTLE is known about the strength of an egg 1 except that for eggs of the same species there is no relation between size and strength, and that differences in strength can be only partly explained by differences in the thickness of the shell ${ }^{1}$; further work was therefore undertaken. A constantly increasing load was applied at the rate of $100 \mathrm{gm}$./sec. to an egg lying lengthwise between two parallel plates of polished hard brass with a Vickers hardness number of $185 \mathrm{kgm}$./sq. mm. The apparatus recorded the increasing load $(w)$ applied to the egg at the two opposed points on its equator, and the diminution in distance $(d)$ between the two plates during loading. The apparatus ceased to record when the shell fractured, thus giving $w_{c}$ and $d_{c}$ at the instant of cracking. The extent of deformation $(d)$ was recorded 120 -fold on a chart. The relation between $w$ and $d$ for a single egg was linear or nearly so. For loads short of $w_{c}$, the deformation was almost entirely recoverable on removing the load. Unless otherwise stated, all the relations mentioned below were highly significant $(P<0.001)$.

The results with 365 hen eggs ranging in weight from about 45 to $65 \mathrm{gm}$. are summarized in Table 1 (where $t$ denotes the thickness of the shell in the region where the crack started). Most of the measure. ments were made on samples of 36 eggs drawn at random from larger batches obtained from different sources at different times of the year. There was little difference between samples, but large differences within samples. For example, sample means for $w_{c} / t$ ranged from only 10.5 to $11.6 \mathrm{kgm} . / \mathrm{mm}$., whereas the range for individual eggs within a sample might be as large as $8-15 \mathrm{kgm} . / \mathrm{mm}$.

Correlation coefficients are given in Table 2. The value of the coefficient for $w_{c}$ with $t$ is as great as, or greater than, that reported by other workers; even so, only about 58 per cent of the variance can be explained by differences in shell thickness. The scatter of the results was so great, in fact, that they could be almost equally well expressed by relating

Table 1

\begin{tabular}{|l|l|c|}
\hline \multicolumn{1}{|c|}{ Property } & Mean & Standard deviation \\
\hline$w_{c}$ (kgm.) & $3.66 \pm 0.042$ & \pm 0.802 \\
$t$ (mm.) & $0.329 \pm 0.002$ & \pm 0.0382 \\
$w_{e} / t$ (kgm. $\left./ \mathrm{mm}.\right)$ & $11.05 \pm 0.088$ & \pm 1.68 \\
$d_{1 / 2}$ (mm. $\left./ \mathrm{kgm}.\right)$ & $0.0475 \pm 0.00061$ & \pm 0.0117 \\
$d_{c}$ (mm.) & $0.167 \pm 0.0015$ & \pm 0.0287 \\
\hline
\end{tabular}

Table 2

$\begin{array}{lc}\text { Relation } & \text { Coefficient }(r) \\ w_{c}: t & +0.761 \pm 0.022 \\ w_{c}: t^{\mathrm{a}} & +0.757 \pm 0.022 \\ w_{c}: d / w & -0.714 \pm 0.026\end{array}$

$w_{c}$ to $t^{2}$ (cf. Table 2). The value of $w_{c} / t$ tended to increase with increasing shell thickness.

The correlation between $w_{c}$ and the slope of the $d-w$ curve was unfortunately not pronounced enough for prediction purposes; if it were, $w_{c}$ could be measured without cracking an egg. Nevertheless, by applying the same load-short of $w_{c}$-to a number of points around the equator of the same egg, it was possible from the values of $d$ to show that the differences within a single egg were too small to account for the differences between eggs. There was no relation between $w_{c}$ and the size of the egg; but its shape had a slight influence, $w_{c} / t$ tending to increase with increasing symmetry $(r$ equalled +0.33 when the breadth of the egg divided by its length was taken as a measure of symmetry). No relation was found between strength-as represented by $w_{c}$ or $w_{c} / t$-and the average number of pores in a unit area of the shell.

When the shell was suitably blackened by an extremely thin coating of silver or by staining it with Verhoeff's stain, a rough estimate of the pressures sustained during loading could be obtained by measuring microscopically the total area of the numerous high lights presumably formed by the plastic deformation of the tips of minute asperities on the shell by the harder plates. The results obtained by applying a number of loads to different regions on the shell of the same egg are set out in Table 3.

Table 3

$w_{c}=4.75 \mathrm{kgm}$. $t=0.41 \mathrm{~mm}$

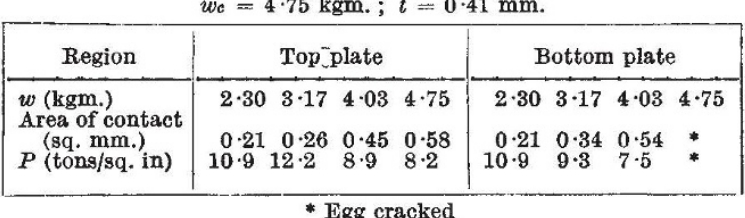

An egg can sustain high pressures without cracking, and it is probable that the values in the table are under-estimates. The shell appears to resemble metallic surfaces in that the real area of contact is nearly proportional to the applied load ${ }^{2}$. Only a very small proportion of the observed values of $d$ was derived from the plastic flattening of surface irregularities, the remainder being derived from the elastic deformation of the shell as a whole.

Using large or small values of $w_{c} / t$ as a criterion of unusual strength or weakness, the strongest ten and the weakest ten eggs were selected from a sample of seventy-two. For each egg the Vickers hardness number of five transverse sections of the shell near the start of the crack was measured with a G.K.N. microhardness tester using a load of $100 \mathrm{gm}$. Three rows of six impressions were made on each section parallel to the inner edge of the shell, and at distances from it of $\frac{1}{4} t, \frac{1}{2} t$ and $\frac{3}{4} t$. A rough estimate of brittleness ${ }^{3}$ was obtained by measuring microscopically the area of superficial shattering that sometimes adjoined the pyramidal impressions. The remainder of the shell and its adhering membranes were analysed for nitrogen (membrane, pore and matrix nitrogen ${ }^{4}$ ), calcium, magnesium, sodium and phosphorus. Analyses for carbonate, potassium, aluminium and iron were started but abandoned; the carbonate 